\title{
Sciendo
}

\section{Qualitative and quantitative Analysis of consumers perception regarding anthropomorphic AI designs}

\author{
Irina ENE \\ Bucharest University of Economic Studies, Romania \\ E-mail: irina3ene@yahoo.com \\ Mihai-Ionuț POP \\ Bucharest University of Economic Studies, Romania \\ E-mail:mihai.pop@digitix.ro \\ Bogdan NISTOREANU \\ Bucharest University of Economic Studies, Romania \\ E-mail: bogdannistoreanu@yahoo.co.uk
}

\begin{abstract}
Business intelligence and analytics are nowadays being integrated into diverse industries, from healthcare to customer relationship management and behavioral profiling, due to the competitive advantages that they offer. Nevertheless, most companies try to integrate as many forms of business intelligence systems as possible into different internal processes. This overall digitization applied to more and more business departments is being analyzed with both curiosity and reluctance. The decision regarding the implementation of innovative forms of automation is taken in an attempt to discover and solve business challenges. However, there are several issues involved, which need to be addressed. One of the risks that are being discussed in the research environment refers to the level of acceptance of artificial intelligence systems. The tolerance and overall readiness of the consumers towards innovation and technology is one of the critical factors which need to be determined before implementing disruptive business intelligence systems. Moreover, in an effort to make devices friendlier to consumers, some developers chose to assign anthropomorphic appearances and even create individual identities for each artificial intelligence system. In this context, it is important for most companies investing in intelligent automation systems to determine to which extend the use of anthropomorphic designs impacts the customer's perception. The objective of this research paper is to analyze the unconscious reaction of consumers towards two opposite designs of artificial intelligence systems: a robotic-like form and a human-like design. Based on this difference, a photo collage was created figuring two pictures: one with a metallic robot having a conversation with a human being and one with a robot with a strong anthropomorphic figure found in the same situation. For the analysis, an eye tracking device was used, in order to measure the point of gaze, the unconscious motion of the eyes, along with the time spent on each fixation and the order in which different elements were fixated upon by the respondents. As the eyetracking device can generate data in various forms, this research includes both qualitative and quantitative analyses of the results, which confirm the same hypothesis, regarding the consumer's preference towards artificial intelligence systems with robotic designs.
\end{abstract}

Keywords: artificial intelligence, consumer's perception, anthropomorphism, eye-tracking, unconscious reaction.

\section{Introduction}

We witness nowadays an increasing use of different forms of automation. Not only the media, but also most industries and political organizations are researching the potential uses of 
artificial intelligence systems, in order to bring their contribution to the switch to a "smart" world, where smart cars, smart homes and smart cities are the new mainstream. This is one of the reasons why the AI evolution is nowadays spectacularly fast. If the development of artificial intelligence was once driven only by simple curiosity of the academic researchers, now the current situation looks completely different. Most enterprises are investing in artificial intelligence research, promoting it outside the academic environment and counting on it to deliver competitive advantages. The evolution of AI is therefore now driven by the great market demand for smart products and services (Pan, 2016) and is adjusting its goals towards the development of AI based on Big Data, Internet Crowd Intelligence, Hybrid Human-Machine Augmented Intelligence and Autonomous Intelligent Systems. All these technology forms are part of what researchers call "Artificial Intelligence 2.0".

Robotics and Artificial Intelligence are completely redefining the value creation chain for most companies (Buxbaum, 2016). They are not only present in the end products and services, but influence the entire processes, from consumer's preferences analysis to manufacturing and distribution.

In this article, we focus on the influence of the implementation of anthropomorphic AI systems on the consumers' preferences. Taking into account this great demand for AI-based products, the study of the consumers' preferences for human-like devices is also of big importance.

Understanding your customers' needs is one of the most important factors that contribute to a firm's profitability (Popa \& Pelau, 2016). Fortunately, analyzing the end users' expectations or standards has been facilitated by the use of various available neuroscience methods. Nowadays, consumers' behavior can be more effectively analyzed, which makes it easier for companies to offer compatible products which are meeting their customers' needs. For example, subjects' brain activity can be examined while watching TV commercials with the goal of monitoring the activity and changes that occur spontaneously. Based on these experiments, the content of the commercials can be evaluated and changed so that the end result will have a greater impact on the effectiveness of the marketing strategy.

Therefore, the implementation of artificial intelligence tools for marketing purposes is being recognized as a priority by most successful companies worldwide. An example here are the neuromarketing tools (Eye-Tracking, Electro Dermal Response, Electroencephalogram, Magnetic Resonance Tomography), which are capable of retrieving unconscious reactions and preferences that cannot be easily explained by subjects, but are primarily based on human behavior that is below the level of conscious awareness. Such instruments are the key to achieving consistency between the consumer decision-making process and marketing strategies and to verify the effectiveness of the applied market policies.

The present article aims to analyze the unconscious reactions of consumers to humanlike artificial intelligence systems and establish certain trends and social responses to this type of technology appearance.

\section{Literature review}

Studies on the influence of artificial intelligence on marketing and consumer behavior talk about the "Digital Age", which introduces the consumers to a new type of doing business: the e-business. This comes along with numerous transformations of old processes into new ones: 
e-invoicing, e-commerce, e-payments (Dirican, 2015), which aim to increase the customers' satisfaction and need for fast types of solutions to their needs. However, such technologies are also creating issues, as for example one of the rivals of the traditional bank system, the so called Bitcoin (e-money) is influencing the financial system and the economy, making it more volatile (Popper, 2015).

The amount of Big Data which can be accessed and analyzed online is constantly growing, as more and more consumers become addicted to the everyday use of technology. The overall digitization applied to more and more processes is being watched with both curiosity and skepticism. Nevertheless, most companies try to integrate as many forms of business intelligence as possible into different business processes.

Business intelligence and analytics, meaning the combination of databases, methods, analytical tools, architectures, and applications to support decision-making systems (Schebesch et al., 2010) is nowadays being used in diverse industries, from CRM and behavioral profiling to healthcare, thanks to the competitive advantages that it has to offer: to discover and solve business challenges. (Minelli et al., 2012). The traditional ways a company is achieving sustainability and efficiency, by minimizing costs or maximizing value are being directly influenced by the development of the artificial intelligence systems.

Disruptive changes emerge by converging different technologies and sciences and redefine the old paths to profitability (Manyika et al., 2013). Studies show that the progress made in the robotics and artificial intelligence fields is faster in the private sector in comparison to the governments (McMaken, 2015). However, there is a discussion about the society's general willingness to accept such technological trends. As a result, numerous studies have been conducted in this direction, analyzing various hypotheses and topics related to the influence of artificial intelligence in the business environment and society.

The level of acceptance of artificial intelligence is nowadays becoming more and more relevant and there are several studies that tackle the trustworthiness of artificial intelligence. The trustworthiness is "the willingness of one party to be vulnerable to the actions of another party, based on the expectation that the other person will perform a particular action that is important to the trustor, regardless of the ability to oversee that party or to control it. This consideration can also be found in the principal-agent theory" (Jensen \& Meckling, 1976).

Another possible definition of trust was formulated by Lee and See. They believe that trust is an attitude towards automation that affects dependency and can be consistently measured, as people ultimately chose to rely on the technology they get to trust. Moreover, trust and guiding reliance is in their opinion the key to the acceptance of automation (Lee \& See, 2004).

But people have different degrees of acceptation or toleration towards technology, and that depends on a number of external and internal factors such as the way of introducing the technological innovation, personal experiences or unique characteristics of individuals. These factors have different meanings and influence each person in a particular way, as people have unique characteristics, based on past experiences, resistance to change, personal beliefs or cultural backgrounds.

A study conducted by Kim \& Buenaflor underlines the importance of early adopters in the acceptability engineering, as they play a crucial role in the diffusion of the innovations (Buenaflor \& Kim, 2012). Furthermore, the readiness in adoption of the various innovative systems is directly influenced by the personal characteristics of the early adopters, such as: 
(1) social status, which includes high education, high incomes and a high tolerance to risks, (2)innovativeness, which translates into favorable attitude towards change, (3) independency in decision making, meaning the characteristic of self-reliance, (4) expertize, understood as experience in using computers, (5) great social participation and (6) information seekers (Kim, 2015).

Consumers' willingness to accept and adapt to disruptive technology by actually using these technologies has also been described by McKnight et al.. He concluded that the initial confidence in the early phase of implementation has a great role, as it is possible to turn this trust over time into reliability and ultimately into faith, understood as the last phase in which the subject not only accepts the new technology, but actually trusts it and refers to it (McKnight et al., 2002)

Lee and See emphasize that if a system is initially untrustworthy, then it will not be used. In this case, the subject will not get to discover its value and, as a result, the initial confidence in the artificial intelligence system is unlikely to grow (Lee \& See, 2004).

The consumers' acceptance towards robots and smart technologies is so important to companies that they do everything necessary to achieve that goal. In an effort to make devices friendlier to consumers, some developers have chosen to use human-like aspects and even create individual identities. As a result, nowadays there are call-center answering machines with names (such as Andreea from Vodafone) or actual robots with names and citizenships (such as Sofia).

Anthropomorphism originates from the Greek: Anthropos, "human" and Morphe, "form" and is defined as the process of mapping cognitive, emotional states and human qualities to objects or other non-living things. Related to the topic of artificial intelligence, the anthropomorphic appearance refers to some features or standards: human face and gestures, natural movement, balanced function and human-like form, autonomy, artificial emotional mechanisms (Duffy, 2003).

The role of anthropomorphic properties in the construction of AI systems is a subject that is currently discussed in detail and different points of view are being debated. For example, according to Gong, the higher the level of anthropomorphic characteristics is assigned to a computer, the more positive social responses are achieved (Gong, 2008).

Opposite results were shown 10 years later by a study by which concluded that consumers prefer the classic devices, rather than various forms of human-like robots. The research attempted to simulate various situations of robotic humanization, but none of them has shown a preference of the consumer over the anthropomorphized devices (Pelau \& Ene, 2018).

Lee and See note that skepticism about the use of technology appears when human decisions are replaced or supplemented by an autonomous machine. The more autonomous a machine is, the more difficult it is to be accepted without people being resistant to this change (Lee \& See, 2004). Discussions about data and private information security are also being followed with great interest, as they constitute issues that the humanity has to deal with more and more nowadays. This topic is not only debated in scientific conferences and researches, but also in social media, which strongly influences the willingness of people to accept the terms and conditions which lead to sharing personal data.

Downsides of AI development are underlined by Professor Roland T. Rust, who states that "although the evolution of AI is very good for enterprises, it is that good for people". As 
businesses are generating more profit, people are losing their jobs, as most of the analytical jobs will soon be automated (Rust, 2017). The same risks are evoked by Roubini and Stiglitz, stating that the rise of unemployment will be a tragic effect to the growing use of robots and innovations, due to the increased efficiency and productivity brought by artificial intelligence (Roubini, 2014; Stiglitz, 2014). Hirst also agrees, predicting that not only will innovation and technological progress lead to unemployment, but the low skilled human work forces will suffer, as they do not have the ability to adapt to the disruptive changes (Hirst, 2014).

While the benefits of implementing intelligent technologies usually outweigh the risks, the real challenge consists in the possibility of rejection of the AI systems by the stakeholders, if their trust technology is lacking. There are individuals which are afraid of the moment when artificial intelligence will overrun human intelligence. The idea that our own creations will transcend our intellect is currently being debated with great interest (Rinesi, 2015). However, a time frame in which this becomes reality is not yet clear. Some experts argue that it will take a long time for people to be able to develop artificial consciousness because there is no documented understanding of how to model human-like motivation, empathy, and social thinking in an artificial intelligence system. But there are others who think that it could only be a technical challenge, and once the engineering boundaries have been overcome, artificial autonomous thinking will become reality (Graziano, 2015).

This article aims to provide a contribution to the study of the level of consumers' acceptance of artificial intelligence devices designed as humans. The influence of the anthropomorphic characteristic of robots will be analyzed on a deep level, as the experiment is meant to recognize and interpret unconscious reactions. The preference for artificial intelligence-based type of assistants with human-like characteristics or for a more robotic appearance will be studied.

\section{Methodology}

The objective of the research is to determine the unconscious reaction of the consumers towards anthropomorphized forms of artificial intelligence versus classic devices. For the analysis of the results an Eye Tracking Device was used. The Eye Tracking Instrument has many applications. Firstly, the eye tracking can deliver unmatched value to the researchers, studying the way in which some products make an impression on consumers. The device is for example able to assess customer attention to key words, package design, advertising, instore navigation or purchase choices. Secondly, the eye tracking device can investigate customer behavior through simulations, such as driving simulators or website testing, giving data about how websites are being viewed and experienced. Furthermore, it is commonly used for providing insights about human-computer interactions, in order to rate the reliability of the computers to human's needs, which brings advantages in the gaming industry, for example, as it is usually used by designers and developers in order to assess and measure the visual attention or reactions during plays, making it easier to find ways to improve the overall gaming experience (Farnsworth, 2017).

Most important of all, the Eye Tracking Tool has become very popular in Neuroscience, Psychology and Education. All these studies create a basis for consumer market researches, as the measure of unconscious reactions towards advertising and products brings a great benefit to the companies and contributes to the purpose of creating value. 
Through Eye-tracking we understand both the research technique and the actual instrument which is used in order to carry out this research. The tool can register the point of gaze and collect the data about the dilation and movements of the pupils, in order to measure the time spent by the eye fixing a certain point. The device is able to measure the unconscious movements, which are very relevant, as they show uncontrolled responses to various stimuli, resulting in much more valuable data. The goal to such an experiment is to analyze which elements or stimuli activate the highest level of attention.

This eye tracking study was designed to analyze the unconscious responses to two different artificial intelligence forms. For this, a photo collage was created, featuring two opposite pictures: on the left side there was a picture with a white metalic robot, standing near a table and being engaged in a conversation with a blond girl, which is holding a glass of water. Several unimportant elements were on the table: a plate and a cookie. The picture from the right showed the robot Sofia engaged in a conversation with a brunette man. Both figures are standing on an empty stage. The robot Sofia is one of the most highly anthropomorphized robots, looking just like a woman, from skin and clothing, facial expressions and gestures that simulate human details, to worldwide recognition for being the first robot to have a citizenship. After this collage, a question appeared: "Which robot of the two would you trust more?". The role of this collage and question is to determine the willingness and tendency of people to favor or reject the anthropomorphic side of robots by taking into account the concept of trust. The collage was displayed for 10 seconds. Of the 19 participants, 17 were female and 2 were male and they were between 23 and 30 years old.

\section{Results and discussion}

The qualitative analysis of the results of the eye tracking experiment, focuses on the Scan Path and Heat Map.

The Scan Path displays the exact path the gaze follows while watching various elements of an image (Rosca, 2017). This analysis consists of circles and lines. The lines show the way where the gaze has moved, without fixing a certain point, while the circles form the fixations, meaning the points where the eyes of the subject stopped. The larger the circle, the more time was allocated to analyze those points.

The analysis of the average results shows that the paths from the part of the photo collage with the robot Sofia are very similar. One reason for this is that this snippet contains few elements that can arouse the subjects' attention. On average, the faces of the man and Sofia were viewed to a great extent and their hands to a less extent. Other items, such as clothing or the environment, were ignored. In the case of the photo with the white robot, several elements were present: a table, a cupcake, a glass of water and a teapot. Still, most of the gaze is focused on the faces of the two subjects and on the attached screen of the white robot, through which he communicates. The radius of the circles in these particular points is larger compared to other points, which means that these elements have attracted more attention.

The heat map displays the most attractive elements of the image to the consumer in the form of "hot" and "cold" points. This type of analysis is one of the most commonly used in eye-tracking research.

The overall results show that the face of the robot Sofia attracted the most attention, figuring shades of red and yellow, while the white robot, which has no anthropomorphic 
design, was not found as interesting as Sofia, his head figuring just shades of green and his display figuring yellowish shades. Neither the clothing nor the hands of the robot Sofia were so much looked at as her face, while in the case of the white robot the mounted screen was studied more than his head. This can mean that in the case of Sofia, who looks like a human, an actual human role was attributed, hence the tendency to look her in the face or even in the eyes. Another reason could be the curiosity, since the robot Sofia has been recently developed and was highly mediatized only in the last year. Because of this, her human appearance awakens curiosity and attention, as she is one of the first anthropomorphized robots to be worldwide known. Another interesting fact is that her head was especially analyzed, as in the picture that was used for the experiment she is revealing a mechanical part on the back of her head, instead of hair. In the case of the white robot, the mounted screen was considered more interesting to look at than his face, since the information is likely to be presented on the screen or the communication is done with the help of this screen.

The quantitative analysis required the selection of areas of interest (AOI), in order to determine specific KPIs for these predefined zones. Table 1 shows the cut out AOIs. For this collage, 5 areas of interest were predefined. Due to the fact that the scan path analysis showed that the subjects' attention was also distracted by the several items from the table, the A0I002 was added to cover this area. The key performance indicators are summarized in Table 2.

Table 1. Areas of interest

\begin{tabular}{|l|l|}
\hline Variable & Description of variable \\
\hline AOI 001 & White robot \\
\hline AOI 002 & Elements on the table \\
\hline AOI 003 & Blond girl speaking with white robot \\
\hline AOI 004 & Brunette man speaking with Sofia \\
\hline AOI 005 & Robot Sofia \\
\hline
\end{tabular}

Source: Authors' own research results

Table 2. Key Performance Indicators

\begin{tabular}{|c|c|c|c|c|c|c|c|c|}
\hline Variable & Sequence & $\begin{array}{c}\text { Entry } \\
\text { time } \\
(\mathbf{m s})\end{array}$ & $\begin{array}{c}\text { Average } \\
\text { fixation } \\
(\mathbf{m s})\end{array}$ & $\begin{array}{c}\text { First } \\
\text { Fixation } \\
(\mathbf{m s})\end{array}$ & $\begin{array}{c}\text { Dwell } \\
\text { time } \\
(\mathbf{m s})\end{array}$ & $\begin{array}{c}\text { Dwell } \\
\text { time }(\boldsymbol{\%})\end{array}$ & $\begin{array}{c}\text { Hit } \\
\text { ratio } \\
(\boldsymbol{\%})\end{array}$ & $\begin{array}{c}\text { Revisits } \\
\text { AOI 001 }\end{array}$ \\
\hline AOI 002 & 6 & 1568.8 & 291.9 & 280.7 & 2219.1 & $22.2 \%$ & $100 \%$ & $19 / 19$ \\
\hline AOI 003 & 1 & 6119.3 & 180.7 & 180.7 & 198.2 & $2.0 \%$ & $63.2 \%$ & $2 / 12$ \\
\hline AOI 004 & 2 & 153.1 & 225.6 & 240.3 & 1841.9 & $18.4 \%$ & $100 \%$ & $19 / 19$ \\
\hline AOI 005 & 5 & 1902.1 & 333.9 & 359.6 & 1968.2 & $19.7 \%$ & $100 \%$ & $19 / 19$ \\
\hline
\end{tabular}

The sequence is an important parameter which shows the order in which the areas of interest were looked at, in which number 1 was the first to be observed and number 5 the last. It can be easily correlated to the Entry Time, which shows how many milliseconds it took for an element to become examined by the eyes of the respondents. On average, the subjects 
first looked at the AOI003 first, with an entry time of $153.1 \mathrm{~ms}$. This means that the majority of subjects looked at the blond woman first. The next AOI was only noticed in the 1072.3 millisecond, and it was the AOI004, the brunette man. The last elements which were gazed are the elements from the table (AOI002), with an entry time of $6119.3 \mathrm{~ms}$.

The average fixation shows the sum of the fixations of a particular AOI and may be presented in milliseconds or percentages, related to the total number of fixations. Analyzing the results of this indicator, we conclude that the AOI005 has been fixed for the largest uninterrupted time, for $333.9 \mathrm{~ms}$. That means that the robot Sofia has attracted the attention of the subjects for large periods of time, in which they studied her in detail. On the second place is the AOI001, the white robot, with an average fixation of $291,9 \mathrm{~ms}$.

The First Fixation indicator shows the same thing, that at the first fixation of AOI005, robot Sofia, the subjects looked at it and analyzed it for an average of 359.6 milliseconds, which is the largest value of this indicator compared to the other AOIs. This means, that the moment the subjects observed Sofia, they spent the biggest period of time analyzing it, before moving their gaze to another point, which shows the curiosity to anthropomorphized designs. The white robot, AOI001, comes on the second place, with 280.7 milliseconds on average.

Considering the Dwell Time Indicator, which shows how much time a particular point was analyzed in total and being the sum of all the fixations in that respective point, we can conclude that a percent of $22.2 \%$ of the 10 milliseconds time was allocated to the white robot. On the second place, the robot Sofia was studied for $19.7 \%$ of the total time for which collage was presented. These results should be analyzed taking into account the fact that the individual fixations were interrupted when the subjects have looked at something else and then recalculated when their eyes have returned to the analyzed AOI.

The last two indicators show the number of subjects who have observed at least once an AOI (Hit Ratio) and the number of subjects who have looked at an AOI, then got distracted by another item and then returned to the same AOI (Revisits). Interesting is that not all people looked at the elements from the table, just $63,2 \%$, so 12 out of 19 subjects and just two of them came back to these elements to view them again.

After the display of the collage, the question appeared: "Which robot of the two would you trust more?". The results show that $75 \%$ of the respondents answered that they would trust the white robot more and only $25 \%$ answered that they would better trust the robot Sofia. These results can be linked to the theory of Lee \& See (2004), which states that the more intelligent a robot appears, the less it will be trusted by humans. The more intelligent a robot is, the more capable, independent or even powerful it can become, which awakens a feeling of insecurity, skepticism or even fear. Although the robot Sofia is still dependent on programming and constant human support, it is seen as a prototype that has a lot of development potential.

\section{Conclusion}

The present work aims to explore the way in which the various forms of artificial intelligence affect consumer behavior and even change our lives. A contribution to the topic of trust in AI systems is brought by this work, as from the analysis of the collage results that consumers have more trust in a normal white robot compared to the robot Sofia, which has an anthropomorphic appearance and proven greater independence. Sofia is one of the first steps 
in the development of new powerful AI systems, which, according to the results of this study, are not yet easily accepted by society.

The analysis of the impact of artificial intelligence forms on the consumer's behavior is more relevant than ever, as smart devices have become a big part of the everyday life. People use applications and smart devices daily for most activities they perform and while the added value is easy to be spotted, there are also risks involved which should not be overlooked: from the use of privacy data as a manipulation technique to the rise of the unemployment, due to the digitization, the evolution of the technology should take into account a clear plan B for future human roles.

This study shows to which extend the technological advances are received with open arms or restraint by society. Since the participants in the experiment were between 23 and 32 years old, it can be said that the results are to be seen as optimistic, as young people are generally more tolerant and have a higher acceptance to disruptive technologies and to change in general.

\section{References}

Buenaflor, C., \& Kim, H.C. (2012). Towards understanding of early adopters as influential users of innovative technologies. International Conference on Computer, Information Systems and Industrial Applications, 520-523.

Buxbaum, O. (2016). Key Insights into Basic Mechanisms of Mental Activity, Springer, doi: 10.1007/978-3-319-29467-4. Retrieved from: http:// www.springer.com/978-3319-29466-7 (accessed on: 12.12.2018).

Dirican, C. (2015). The Impacts of Robotics, Artificial Intelligence On Business and Economics. Procedia - Social and Behavioral Sciences, 95, 564-573. doi:10.1016/j.sbspro.2015.06.134.

Duffy, B.R. (2003). Anthropomorphism and The Social Robot. Robotics and Autonomous Systems. Special Issue on Socially Interactive Robots, 42(3-4), 177-190.

Farnsworth, B.(2017). Eye Tracking: The Complete Pocket Guide, Retrieved from: https://imotions.com/eye-tracking/ (accessed on: 12.12.2018).

Gong, L.(2008). How social is social responses to computers? The function of the degree of anthropomorphism in computer representations. Computers in Human Behavior, 24, 1494-1509.

Graziano, M. S. A. (2015). Build-a-brain: We could build an artificial brain that believes itself to be conscious. Does that mean we have solved the hard problem? Retrieved from: https://aeon.co/essays/can-we-make-consciousness-into-an-engineering-problem (accessed on: 2.01.2019).

Hirst, T. (2014). Does technological innovation increase unemployment? The World Economic Forum Blog, Retrieved from: https://agenda.weforum.org/2014/11/doestechnological-innovation-increaseunemployment (accessed on: 2.01.2019).

Jensen, M., C., Meckling, W., H.(1976). Theory of the firm: Managerial behavior, agency costs and ownership structure, Journal of Financial Economics, 3(4), 305-360.

Kim, H.C. (2015). Acceptability engineering: the study of user acceptance of innovative technologies, Journal of Applied Research and Technology, 13, 230-237.

Lee, J.D., See, K.A. (2004). Trust in automation: designing for appropriate reliance. Human Factors, 46(1), 50-80. 
Manyika, J., Chui, M.; Bughin, J.; Dobbs, R.; Bisson, P.; Marrs, A. (2013). Disruptive technologies: Advances that will transform life, business, and the global economy, McKinsey Global Institute, San Francisco.

McKnight, D.H., Choudhury, V., Kacmar, C. (2002). The impact of initial consumer trust on intentions to transact with a web site: a trust building model. Journal of Strategic Information Systems, 11(3), 297-323.

PICBE | 716

McMaken, R. (2015). NASA: Give Us More Money So We'll Discover Alien Life. Retrieved from: https://mises.org/blog/nasa-give-us-more-money-so-well-discover-alien-life (accessed on: 21.12.2018).

Minelli, M., Chambers, M.,; Dhiraj, A. (2012). Big data, big analytics: Emerging business intelligence and analytic trends for today's businesses. John Wiley \& Sons, Hoboken.

Pan, Y. (2016). Heading toward Artificial Intelligence 2.0., Engineering, 2(4), 409-413. doi:10.1016/j.eng.2016.04.018.

Pelau, C., M.; Ene, I. (2018). Consumers perception on human-like artificial intelligence devices, 1-7. Fourth International Conference on New Trends in Sustainable Business and Consumption (BASIQ), Heidelberg, 197-203.

Popa, A., Pelau, C. (2016). Differences in the clothing brand perception depending on generation, Industria Textila, 4, 260-264.

Popper, N. (2015). Can Bitcoin Conquer Argentina? Retrieved from: http://www.nytimes.com/2015/05/03/magazine/howbitcoin-is-disruptingargentinas-economy.html (accessed on: 14.11.2018).

Rinesi, M. (2015).The price of the Internet of Things will be a vague dread of a malicious world, Retrieved from : https://ieet.org/index.php/IEET2/more/ rinesi20150925 (accessed on: 2.01.2019).

Rosca, M. I. (2017). Metode de cercetări de marketing utilizate în publicitate, Editura ASE, 2017, 67-95.

Roubini, N. (2014). Rise of the Machines: Downfall of the Economy. Retrieved from: http://www.roubinisedge.com/nouriel-unplugged/rise-of-themachines-downfall-ofthe-economy? (accessed on: 14.11.2018).

Rust, R.(2017). Artificial Intelligence in Service, 8th EMAC Regional Conference, Timisoara, Romania.

Schebesch, K.B., Pop, N.Al., Pelau, C. (2010). A New Paradigm in Contemporary Marketing Computational Marketing, Romanian Journal of Marketing 1(2), 36-73.

Stiglitz, J.E. (2014), Unemployment And Innovation. Working Paper 20670. National Bureau Of Economic Research 1050, Retrieved from: http://www.nber.org/papers/w20670 (accessed on: 2.01.2019). 